\title{
REFLEXÕES SOBRE A PÓS-GRADUAÇÃO PARA A FACULDADE DE DIREITO
}

\author{
Carlos Gilberto Carlotti Junior ${ }^{1}$
}

A pós-graduação brasileira finalizou em 2020 um Plano Nacional de PósGraduação (PNPG 2011-2020), assim como um quadriênio de avaliação (2017-2020). Além disso, estamos vivenciando em 2020 e em 2021 uma pandemia de proporção inesperada, com grandes mudanças na sociedade e, também, na pós-graduação. A USP celebrou em 2019 seus 50 anos do modelo atual de pós-graduação após a regulamentação nacional, pelo parecer Sucupira (CFE 977/65), incluindo as fases de criação de programas, expansão e consolidação. Todos esses fatos devem ser analisados e mostram que encerramos um ciclo na pós-graduação e precisamos nos preparar adequadamente para o futuro.

O conhecimento da realidade nacional da pós-graduação atual e futura, das necessidades da sociedade e das características e dos objetivos de nossa universidade são fundamentais para que possamos manter a USP como a mais importante universidade brasileira na pesquisa e na formação de alunos diferencialmente qualificados. É fundamental que, para este novo ciclo da pós-graduação, ações e metas sejam definidas, estabelecendo um planejamento estratégico norteador de nossas condutas. Esta tarefa deve envolver docentes, alunos(as) e servidores(as).

O PNPG previa, entre outros objetivos, a expansão do sistema nacional de pós-graduação e a diminuição de diferenças regionais. A expansão atingiu o objetivo esperado, sendo que, em 2019, foram titulados no Brasil cerca de 55.000 mestres e 24.000 doutores, com uma diminuição importante das diferenças regionais pela consolidação de programas em todos Estados brasileiros.

É fundamental que a comunidade da pós-graduação da USP faça a leitura correta de quais serão as grandes diretrizes do próximo Plano Nacional de Pós-Graduação. Por exemplo, a expansão do sistema nacional será mantida? Nos últimos anos e talvez nos próximos, é sinalizada pela agência de gestão e fomento da pós-graduação no Brasil, a Capes, a dificuldade em manter seu orçamento para bolsas e fomento. Além disso, o número de titulados por docente no Brasil é considerado elevado para os padrões mundiais. Portanto, interpreto que a expansão não será uma prioridade nos próximos anos. Provavelmente, teremos a qualidade da formação do(a) aluno(a) e o impacto das pesquisas decorrentes das teses e dissertações como os objetivos principais do novo PNPG. A preocupação não será quantos(as) alunos(as) são formados(as), mas, sim, como foi a formação desses(as) alunos(as), qual é o destino dos egressos da pós-graduação,

Pró-Reitor de Pós-Graduação da Universidade de São Paulo. 
qual é a colaboração da pós-graduação em suas carreiras acadêmicas e profissionais e quais são os impactos das pesquisas envolvidas na formação dos(as) alunos(as).

Essas mudanças estão plenamente de acordo com os objetivos da pósgraduação da USP, que são os de formar alunos(as) qualificados(as), com liderança nas suas áreas de atuação, e realizar pesquisas qualificadas e de vanguarda. Todos os envolvidos na pós-graduação precisam planejar ações para que esses objetivos sejam alcançados, incluindo ainda entre essas metas a busca por ingressantes qualificados, a revisão das disciplinas, a discussão com os(as) alunos(as) sobre a carreira após a pósgraduação, a criação de um ambiente de pesquisa adequado, a escolha de temas relevantes a serem estudados e a divulgação adequada dos resultados dos trabalhos realizados.

Em relação à avaliação da pós-graduação, a perspectiva é de uma mudança significativa, com a adoção de um sistema multidimensional analisando cinco dimensões: formação de egressos; internacionalização; produção científica; inovação e transferência de conhecimento; e impacto e relevância econômica e social. Ainda não existe uma definição completa desse modelo, mas a perspectiva é de que a qualidade na formação e o impacto da pesquisa sejam itens importantes a serem considerados. De forma simplista, a avaliação considerará não somente quanto foi realizado, como, por exemplo, o número de publicações ou o impacto da revista em que o trabalho foi publicado, mas, também, a importância do trabalho, a atividade do egresso e o impacto da pesquisa - entendendo como impacto várias possibilidades, tais como mudanças sociais, implementação de políticas públicas, inovação, tecnologias desenvolvidas, entre outros.

Em relação à pandemia, teremos nos próximos anos mudanças sociais importantes e algumas permanentes. Para a pós-graduação, é possível prever alguns efeitos, como a diminuição da mobilidade no país e no exterior e o aperfeiçoamento de novas tecnologias de ensino. A menor mobilidade, provavelmente, será suavizada pela participação on-line em bancas, disciplinas e reuniões. Precisamos garantir que esse processo seja conduzido com a manutenção da qualidade, além de aprimorar as tecnologias necessárias para essa finalidade. Em relação ao ensino, provavelmente teremos a convivência do modelo presencial e on-line, sendo que este último, se bem utilizado, pode permitir maior participação de professores externos à universidade, inclusive do exterior, e maior contato entre os alunos e os professores, tornando o ensino ativo e participativo. É importante salientar que, para uma universidade de pesquisa como a USP, a presença dos alunos e professores interagindo presencialmente é fundamental. Portanto, as atividades on-line devem ser utilizadas para o aperfeiçoamento e aprimoramento das atividades presenciais, e não em substituição a elas.

Tenho certeza de que a Faculdade de Direito da USP, que está na vanguarda nacional do ensino da pós-graduação, saberá fazer as reflexões necessárias para o futuro e definir uma estratégia que atenda aos anseios da comunidade das Arcadas e da USP. 